\title{
Approaches for quantifying antimicrobial consumption per animal species based on national sales data: a Swiss example, 2006 to 2013
}

LP Carmo ${ }^{1}$, G Schüpbach-Regula ${ }^{1}$, C Müntener ${ }^{2}$, A Chevance ${ }^{3}$, G Moulin ${ }^{3}$, I Magouras ${ }^{1}$

1. Veterinary Public Health Institute, Vetsuisse, University of Bern, Switzerland

2. Institut für Veterinärpharmakologie und -toxikologie, Vetsuisse, University of Zurich, Switzerland

3. Anses - French Agency for Food, Environmental and Occupational Health \& Safety, France

Correspondence: Luís Pedro Carmo (luis.gomesdocarmo@vetsuisse.unibe.ch)

Citation style for this article:

Carmo LP, Schüpbach-Regula G, Müntener C, Chevance A, Moulin G, Magouras I. Approaches for quantifying antimicrobial consumption per animal species based on national sales data: a Swiss example, 2006 to 2013. Euro Surveill. 2017;22(6):pii=30458. DOI: http://dx.doi.org/10.2807/1560-7917.ES.2017.22.6.30458

Article submitted on 27 May 2016 / accepted on 15 November 2016 / published on 09 February 2017

Antimicrobial use in animals is known to contribute to the global burden of antimicrobial resistance. Therefore, it is critical to monitor antimicrobial sales for livestock and pets. Despite the availability of veterinary antimicrobial sales data in most European countries, surveillance currently lacks consumption monitoring at the animal species level. In this study, alternative methods were investigated for stratifying antimicrobial sales per species using Swiss data (2006-2013). Three approaches were considered: (i) Equal Distribution (ED) allocated antimicrobial sales evenly across all species each product was licensed for; (ii) Biomass Distribution (BMD) stratified antimicrobial consumption, weighting the representativeness of each species' total biomass; and (iii) Longitudinal Study Extrapolation (LSE) assigned antimicrobial sales per species based on a field study describing prescription patterns in Switzerland. LSE is expected to provide the best estimates because it relies on field data. Given the Swiss example, BMD appears to be a reliable method when prescription data are not available, whereas ED seems to underestimate consumption in species with larger populations and higher treatment intensity. These methods represent a valuable tool for improving the monitoring systems of veterinary antimicrobial consumption across Europe.

\section{Introduction}

Antimicrobial resistance has been gaining momentum as one of the most important topics within the public health sphere [1]. Part of the antimicrobial resistance burden for public health lies on the use of antimicrobials for veterinary purposes. Results from several studies have suggested that antimicrobial exposure in livestock is contributing to the emergence, selection and spread of antimicrobial resistant bacteria [2-4]. In addition, it is known that the use of antimicrobials in pets influences the resistance patterns found in those animals [5]. The subsequent spread of resistant bacteria from animals to humans can occur through multiple potential routes.

Monitoring systems in veterinary medicine can provide useful insights into temporal trends of antimicrobial consumption and ensure compliance with prudent usage practices, programmes or regulations. Furthermore, they can assist in identifying the most efficient interventions for optimising antimicrobial usage. When combined with antimicrobial resistance data, quantification of antimicrobial usage can be useful not only in identifying risk factors for the emergence of resistance, but also in describing temporal associations between antimicrobial usage and resistance $[6,7]$. Finally, monitoring systems can be a source of highly informative data for boosting research on the complex topic of emergence, selection and spread of antimicrobial resistance. Thus, monitoring antimicrobial consumption in livestock and companion animals is undoubtedly an important tool in the battle against antimicrobial resistance.

Research on the veterinary use of antimicrobials has focused on livestock species because their populations are larger and their antimicrobial consumption is higher than that of pet animals. Recognition of the importance of quantifying antimicrobial use in livestock emerged more than a decade ago [8] and the European Commission and the European Medicines Agency (EMA) have also emphasised the importance of monitoring antimicrobial use [9-11]. There is no binding European Union (EU) legislation with respect to the implementation of such monitoring programmes at national level and it is up to each country to define its strategy. 
In Switzerland, a non-EU country, the legal basis for sales data collection was defined in Article 35 of the Federal Ordinance on Veterinary Medicinal Products, enacted in September 2004 [12].

The European Surveillance of Veterinary Antimicrobial Consumption (ESVAC) project, initiated in 2010 by the EMA, has contributed considerably to the collection of standardised data on veterinary consumption in Europe [13]. ESVAC reports are published annually and are currently based on data provided by 26 countries, including Switzerland [14].

Prompted by the European Commission's Action plan against the rising threats from Antimicrobial Resistance [10], ESVAC published guidance for data collection on antimicrobial consumption at the species level [15]. Furthermore, international guidelines such as the World Organisation for Animal Health's Terrestrial Animal Health Code [7] and Integrated Surveillance of Antimicrobial Resistance: Guidance from a WHO Advisory Group [16], mention usage data at the species level as an important aspect that should be considered in monitoring systems. Data at the species and the production type level (such as dairy or beef cattle; broilers or laying hens; breeding, farrowing or fattening units) provide a better estimate of the antimicrobial exposure in each population and are therefore much more informative than overall sales data.

In mid-2000, Denmark implemented an automated system for nationwide collection of antimicrobial prescription data for production animals (pigs, poultry, cattle, sheep, goats, fish and mink) [6]. Systems providing data at the farm level can be used to identify high consumers and therefore implement benchmarking systems based on usage by individual farms or practitioners [17-19]. However, such systems can be very demanding in terms of resources and infrastructure [16] which might hinder their establishment.

In the absence of automated data collection schemes, alternatives need to be explored. ESVAC suggests that estimates of antimicrobial usage per species can be obtained through cross-sectional or longitudinal studies or based on data from marketing authorisation holders [15]. Some of these strategies have already been applied. In the Netherlands, longitudinal data on antimicrobial usage were collected from a sample of farms [20]. In France, antimicrobial consumption per animal species has been calculated based on estimates of marketing authorisation holders since 2009 [21].

In Switzerland, antimicrobial sales data have been obtained yearly at national level since 2004 by requesting the number of packages sold per product from the marketing authorisation holders [22]. However, this strategy does not enable quantification of antimicrobial consumption at the species level.
There is no standardised method for quantifying the distribution of antimicrobial sales per animal species. The choice of the method also depends on data availability. It is therefore of interest to compare different possible methods and observe how results vary.

The aim of this study was to propose and compare alternative methods for estimating the antimicrobial consumption in pet and livestock animal species or groups of species in Switzerland by combining sales data with (i) summary of product characteristics; (ii) summary of product characteristics and animal demographic data; (iii) prescription data from a longitudinal study.

\section{Methods}

\section{Antimicrobial sales data and product information}

Based on information obtained from marketing authorisation holders, the number of antimicrobial packages sold per product is converted into the corresponding amount of active ingredient. The results are published in the ARCH-Vet report (the official annual report on sales of antibiotics in veterinary medicine and antibiotic resistance monitoring of livestock in Switzerland) by the Federal Food Safety and Veterinary Office (FSVO) [23].

The FSVO granted the authors access to the detailed antimicrobial sales database. The models developed in this study were fed with sales data from the period 2006-2013. Results from these models are a proxy for antimicrobial consumption.

Antimicrobial products were categorised into two groups: monospecies products (authorised for a single species) and multispecies products (licensed for multiple species). This stratification was done by extracting from the Swiss Veterinary Drug Compendium data on the species each product is licensed for [24]. The following species or groups of related species (hereafter referred to as 'species') were considered: pigs, cattle, poultry, small ruminants (goats and sheep grouped together), horses and pets (cats and dogs grouped together). Poultry is roughly equivalent to the number of chickens because turkey or waterfowl production in Switzerland is negligible. It should also be noted that, in Switzerland, most horses are kept for leisure and only a small number enter the food chain.

Rabbits and fish were excluded as their population sizes are comparatively small, and therefore these groups are expected to represent a negligible contribution to the consumption of antimicrobials in Switzerland.

\section{Animal demographic data}

The national total biomass of each species was calculated from 2006 to 2013 using the population correction unit (PCU) method. PCU is a technical unit of measurement. One PCU is equivalent to $1 \mathrm{~kg}$ of 
biomass of livestock and slaughtered animals [13]. For livestock, theoretical weights at the most likely time for treatment were based on ESVAC recommendations [15]. For cats and dogs we used $5 \mathrm{~kg}$ and $20 \mathrm{~kg}$ bodyweight, respectively, as these are accepted standards for drug regulatory agencies [25].

When possible, sources of demographic data used for the ESVAC report were consulted [26]. For pets, demographic data were collected from the Société pour l'alimentation des animaux familiers (Swiss Society for Pet Nutrition) $[27,28]$. For the years where no data were available $(2009,2011,2013)$, the mean of the previous and the following year was used.

\section{Field data on antimicrobial prescription patterns}

Regula et al. (2009) assessed the prescription patterns of veterinarians in Switzerland for the period 2004-2005 [29]. Eight veterinary practices, representing $1.5 \%$ of all veterinary clinics in Switzerland (with a total of 15 veterinarians), were selected based on the proportion of owners keeping livestock and the use of electronic databases for disease and prescription records. Cattle, pigs, sheep, goats, horses, dogs and cats were included in this study. The proportion of animals at risk of being treated in the field study relative to the total number of animals in the country varied across the different animal species. To take this into account, the total amount of active ingredient prescribed was divided by the percentage of animals of each species at risk of being treated. The number of animals at risk of being treated during the field study were calculated as follows: (i) for horses, the number of owners in the practice records was used as a proxy for the number of animals (ii) for pets, the number of owners in the practice records was multiplied by the mean number of pets per household in Switzerland [27,28]; (iii) for pigs and cattle, veterinarians enrolled in the study provided estimates of the number of animals on the farms they visited; (iv) the number of small ruminants at risk of being treated was calculated based on the number of cattle at risk of being treated. We assumed that the ratio of cattle to small ruminants in the field study was the same as at the national level [26].

Field data were used to estimate the distribution of antimicrobial consumption by different species. These estimates were used to calculate mode values of Program Evaluation and Review Technique (PERT) distributions used in the Longitudinal Study Extrapolation (LSE) model described in detail below.

\section{Distribution of antimicrobial sales per species}

Three different methods were used to extrapolate antimicrobial usage per species from sales data: Equal Distribution (ED), Biomass Distribution (BMD) and Longitudinal Study Extrapolation (LSE). Each method was exemplified using Swiss data, allowing for the calculation of estimates of antimicrobial consumption for several animal species from 2006 to 2013. Data analyses were performed using $\mathrm{R}$ statistical software [30].

Consumption estimates are presented in mg per PCU when referring to total national consumption and in $\mathrm{mg}$ per kg of biomass when describing the consumption by specific animal species.

\section{Equal Distribution}

ED assumed that antimicrobial consumption was equal for each species a product was licensed for. Thus, the amount of antimicrobial product used by a species in a given year was calculated as follows:

$$
C_{p_{a}, \text { spec }_{a}, y_{a}}=\frac{S_{y_{a}}}{\sum s p e c_{\mathrm{n}}}
$$

C: Consumption estimate; pa: a given product; ya: a given year; speca: a given species for which a product is licensed; specn: all the species for which a product is licensed; S: amount of product in sales.

The model was developed on a product basis. Calculated amounts of active ingredient belonging to the same antimicrobial class were summed for each year and animal species.

\section{Biomass Distribution}

In this method, the amount of product sold (in 2006-2013) was distributed proportionally to the relative importance of a species' total biomass at a national level. The analysis was done for each product individually, taking into account the animal species the product is licensed for and the corresponding annual biomass values. The calculation for every product was performed as follows:

$C_{p_{a}, \text { spec }_{a}, y_{a}}=S_{y_{a}} * \frac{B M_{\text {spec }_{a}, y_{a}}}{\sum B M_{\text {spec }_{\mathrm{n}}, y_{a}}}$

C: Consumption estimate; pa: a given product; ya: a given year; speca: a given species a product is licensed for; specn: all the species a product is licensed for; $S$ : amount of product in sales; BM: biomass.

Finally, the results were summed up for every combination of animal species, antimicrobial class and year.

\section{Longitudinal Study Extrapolation}

In this approach, estimates of the antimicrobial sales repartition per species (i.e. the amount of antimicrobials sold for use by each species) were derived from a Monte Carlo simulation, using PERT distributions to model the uncertainty of the data derived from the longitudinal study. This type of beta distribution is generated from three values: minimum (Min), mode and 
maximum (Max). PERT distributions were created for every combination of antimicrobial class, year and animal species. The values in these distributions ranged from 0 to 1 and represented proportions of the total amount of sales for the respective antimicrobial class in a given year.

Min and Max were calculated by combining sales data with information from the Swiss Veterinary Drug Compendium [24]. Min was estimated by summing the amounts of monospecies products sold for each combination of antimicrobial class, animal species and year. Max was calculated as the sum of the amounts sold of all the products (monospecies and multispecies products) of a certain antimicrobial class licensed for a specific species, in a specific year.

Both Min and Max values were converted into a proportion of the total amount of antimicrobial for the same combination of antimicrobial class and year. In summary, Min and Max were calculated as follows:

$$
\begin{aligned}
\operatorname{Min}_{\text {spec }_{a}, y_{a}, A M C_{a}}= & \frac{\sum \text { Mono }_{\text {Spec }_{a}, y_{a}, A M C_{a}}}{S_{y_{a}, A M C_{a}}} \\
\operatorname{Max}_{\text {spec }_{a}, y_{a}, A M C_{a}}= & \frac{\sum \text { Mono }_{\text {spec }_{a}, y_{a}, A M C_{a}}+\sum \text { Multi }_{\text {spec }_{a}, y_{a}, A M C_{a}}}{S_{y_{a}, A M C_{a}}}
\end{aligned}
$$

Min: minimum of the PERT distribution; Max: maximum of the PERT distribution; Mono: monospecies products; Multi: multispecies products; speca: a given species a product is licensed for; ya: a given year; AMCa: a given antimicrobial class; S: amount of product in sales.

Mode values of the PERT distributions were based on data from the field study on antimicrobial prescription patterns in Switzerland [29]. Specifically, the total amount of active ingredient from each antimicrobial class prescribed for each species was divided by the total amount of authorised products for that same species and antimicrobial class. This value was then used to estimate a mode value between the Min and the Max. The mode for each combination of species, antimicrobial class and year was calculated as follows:

$$
\begin{aligned}
& \text { Mode }_{\text {Spec }_{a}, y_{a}, A M C_{a}} \\
& =\left(\frac { F _ { \text { Mono } _ { \text { Spec } _ { a } , A M C _ { a } } } + F _ { \text { Multi } _ { \text { Spec } } , A M C _ { a } } } { F _ { \text { Mono } _ { \text { spec } _ { n } , A M C _ { a } } } + F _ { \text { Multi } _ { \text { spec } _ { n } , A M C _ { a } } } } * \left(\text { Max }_{\text {spec }_{a}, y_{a}, A M C_{a}}\right.\right. \\
& \left.- \text { Min }_{\text {spec }_{a}, y_{a}, A M C_{a}}\right)+\operatorname{Min}_{\text {spec }_{a}, y_{a}, A M C_{a}}
\end{aligned}
$$

Mode: mode of the PERT distribution; F: amount of antimicrobial from the field study; Min: minimum of the PERT distribution; Max: maximum of the PERT distribution; Mono: monospecies products; Multi: multispecies products; speca: a given species a product is licensed for; ya: a given year; AMCa: a given antimicrobial class; specn:: all the species a product is licensed for.

Poultry was not included in the field study, and therefore mode values for the PERT distributions of this species group were calculated as the mean value of the Min and Max for each year.

The mode values were standardised so that they added up to 1 for each combination of antimicrobial class and year. For this, the mode values were recalculated proportionally to their species distribution in the longitudinal study.

The simulation model was then run 10,000 times, using the R package 'mc2d' [31], and the mean of the results of each iteration was calculated. This result represented the proportion of the total sales of a certain antimicrobial class in a given year that was sold for consumption by a given animal species. Due to the stochasticity of the model and the skewness of some distributions (particularly when the mode value was close to the Min or Max), the sum of the repartition per species was often different from $100 \%$ for each year/ antimicrobial class combination. For that reason, the repartition values were standardised proportionally to each species estimates. The $95 \%$ credibility intervals for each estimate were calculated using the R package 'stats' [30]. Finally, these values were used to estimate, for each antimicrobial class and year, the amount of antibiotics sold for use by each of the animal species.

For the three models, results are presented at an antimicrobial class level as the total amount of antimicrobials sold in $\mathrm{kg}$ and as $\mathrm{mg}$ of active ingredient sold per $\mathrm{kg}$ biomass.

Due to confidentiality reasons, no results disclosing the sales of individual products or marketing authorisation holders can be presented. Thus, sales at an antimicrobial class level are not shown for some species.

\section{Results}

\section{Descriptive statistics: veterinary antimicrobial} sales data from Switzerland, 2006-2013

From 2006 to 2008 there was an increase in the sale of veterinary antimicrobial products from $67,423 \mathrm{~kg}$ of active ingredient to $72,300 \mathrm{~kg}$. Starting in 2008 , a steady decrease in sales was observed, resulting in a total reduction of $26.2 \%$ by 2013 .

The amount of monospecies products sold throughout the study period ranged from $24.9 \%$ (2011) to $30.1 \%$ (2006) of the total amount of antimicrobial product sold. Multispecies products authorised for two species represented $51.6-56.4 \%$ of the total amount of antimicrobial sold in each of the 8 years considered.

When the total sales were converted into mg per PCU, it was observed that variations in animal demographics 
Distribution of total antimicrobial sales per species according to the three different approaches. Switzerland, 2006-2013

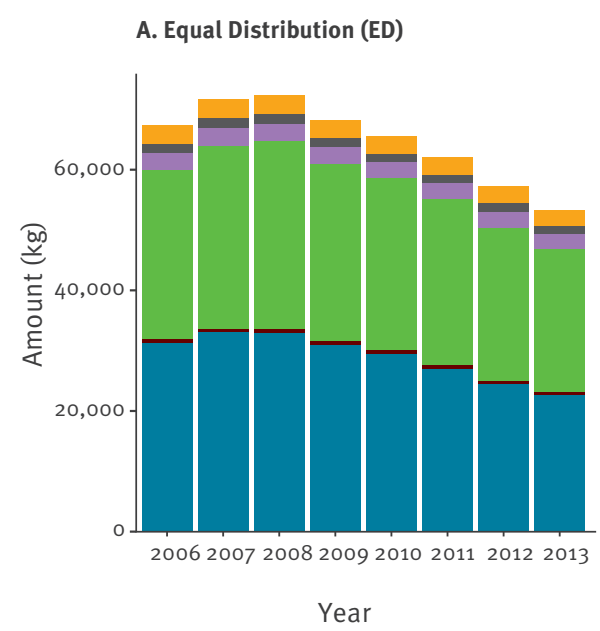

Species

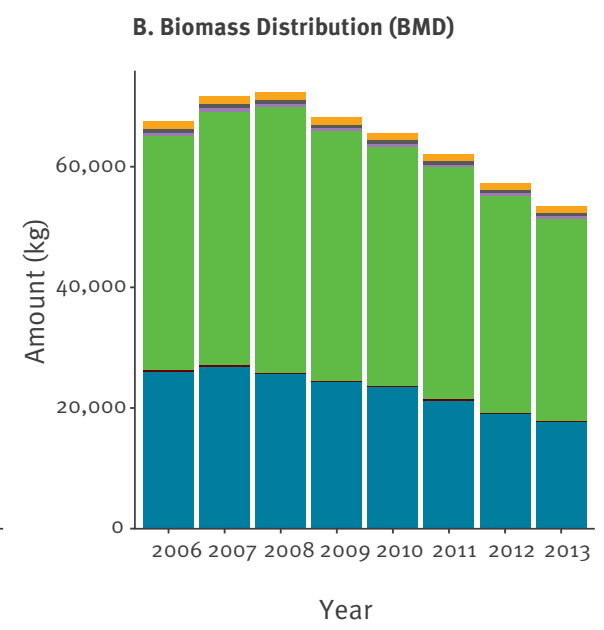

Year

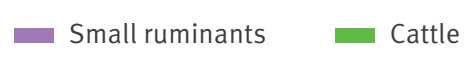

D. Longitudinal Study Extrapolation (LSE)

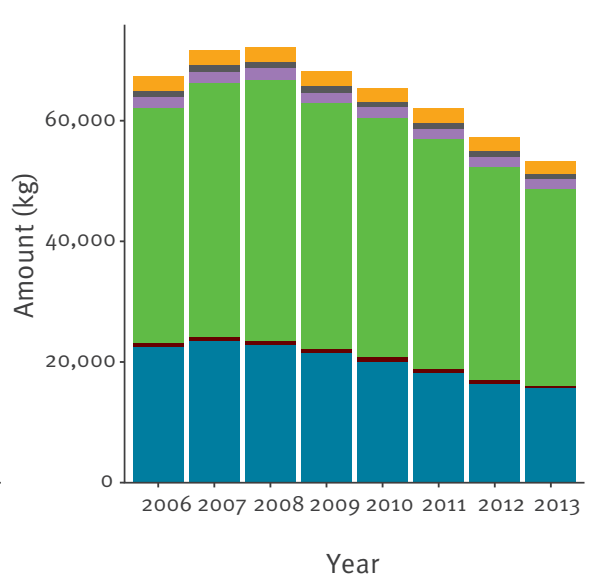

Doultry Pigs

Equal Distribution (ED): equal sales repartition by the species the products are licensed for.

Biomass Distribution (BMD): sales repartition based on the relative total biomass of the species in the country.

Longitudinal Study Extrapolation (LSE): sales repartition based on results from a previous field study. Pets are defined as cats and dogs, while small ruminants include goats and sheep. Horses are included as a leisure/sports species.

did not influence the antimicrobial consumption pattern. Sales per PCU peaked in 2008 (87.9 mg/PCU); in 2013 , the sale of veterinary antimicrobial products reached a minimum of $64.5 \mathrm{mg} / \mathrm{PCU}$ (Table 1 ).

PCU: population correction unit.

'Others' includes amphenicols, quinolones (other than fluoroquinolones), lincosamides, pleuromutilins

Sulfonamides, tetracyclines and penicillins were the antimicrobial classes sold the most throughout the years. Their contribution to the total sales ranged from $81.7 \%$ to $82.3 \%$ of the total mg per PCU. In parallel, sulfonamides and tetracyclines were the antimicrobial classes that contributed most to the observed decrease in antimicrobial consumption from 2008 to 2013, with decreases of 12.5 and $6.3 \mathrm{mg}$ per PCU, respectively.

\section{Equal Distribution}

ED estimated that most of the antimicrobials ( $\min -\max$, 2006-2013) were sold for use in pigs (42.6-46.4\%) and cattle (41.4-44.1\%). Over the years, a decrease in the sale of antimicrobials for pigs was observed. However, the proportion of antimicrobials sold for cattle increased, despite a reduction in the total amount of antimicrobials sold for this species (Figure 1).

The estimates for poultry revealed a negligible contribution to the overall sales (0.9-1.1\%).
When using $\mathrm{mg}$ of antimicrobial per $\mathrm{kg}$ biomass $(\mathrm{mg} /$ $\mathrm{BM})$ as a consumption metric, pets (145.4-179.5 mg/ $\mathrm{BM})$ and pigs (110.0-160.0 mg/BM) were the species that seemed to be under the greatest antimicrobial pressure. Antimicrobials for cattle ranged from 48.8 to $64.5 \mathrm{mg} / \mathrm{BM}$ (Table 2).

\section{Biomass Distribution}

Estimates from this model highlighted cattle as the species for which most antimicrobials were sold, with an increase in percentage from $57.6 \%$ in 2006 to $62.7 \%$ in 2013. Despite this result, the total amount of antimicrobials sold for cattle decreased from $38,809 \mathrm{~kg}$ to $33,446 \mathrm{~kg}$ in the same period. For pigs, percentages ranged from $38.7 \%$ in 2006 to $33.1 \%$ in 2013 . For other species, the repartition estimates varied as follows: pets $1.7-1.9 \%$; small ruminants $0.8-0.9 \%$; horses $0.8-0.9 \%$; poultry $0.3-0.9 \%$.

Using $\mathrm{mg} / \mathrm{BM}$ as a consumption metric, the values for the three main livestock species were between 86.3-124.4 mg/BM for swine, 69.3-90.9 mg/BM for cattle and 4.3-6.2 mg/BM for poultry (Table 2).

\section{Longitudinal Study Extrapolation}

With the exception of small ruminants (for which antimicrobial sales were relatively stable throughout the years), the LSE model calculated a reduction in antimicrobial consumption over time for all species. Total consumption of antimicrobials by cattle as 

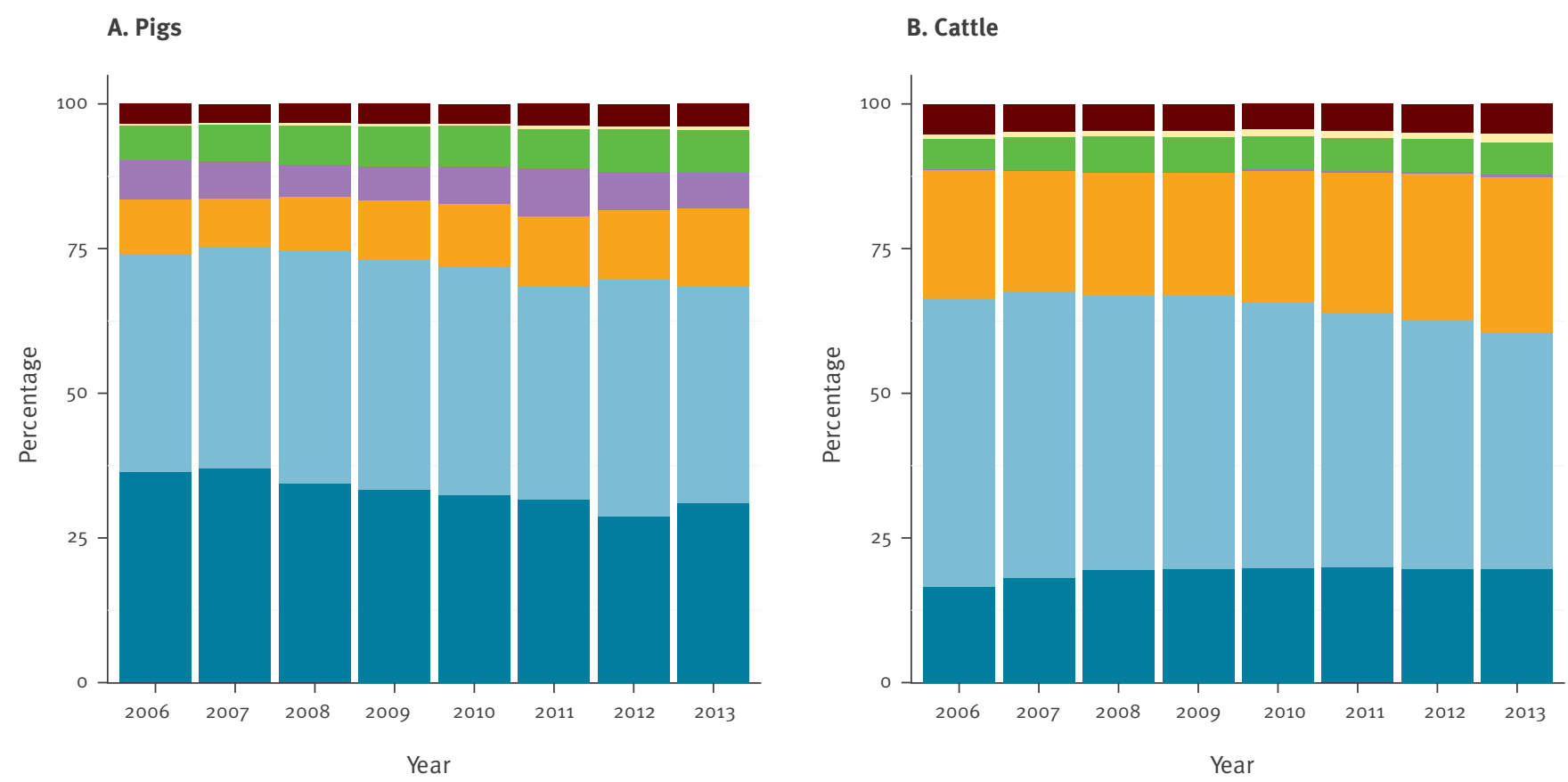

Antimicrobial class

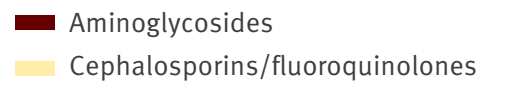
Macrolides
Others

Penicillins
Sulfonamides/trimethoprim

Tetracyclines

The estimates were obtained through the Longitudinal Study Extrapolation (LSE) approach: sales repartition based on results from a previous field study. 'Others' includes amphenicols, quinolones (other than fluoroquinolones), lincosamides, pleuromutilins and polymixins.

a percentage of consumption by all species was lowest in 2006 , at $57.6 \%(33.2-72.8 \%)$ (mean (minimum of the $95 \%$ credibility interval-maximum of the $95 \%$ credibility interval)) and highest in 2012 , at $61.8 \%$ (35.7-78.3\%). The consumption of antimicrobials by pigs went in the opposite direction, with a minimum of $28.8 \%(12.4-55.1 \%)$ in 2012 and a maximum of $33.4 \%$ $(17.9-58.1 \%)$ in 2006 .

Despite some differences in terms of the relative proportion of consumption of different antimicrobial classes (Figure 2), estimates for pigs and cattle decreased over time in terms of $\mathrm{mg} / \mathrm{BM}$ : the estimated consumption by cattle dropped from $81.6 \mathrm{mg} / \mathrm{BM}$ (47.1-103.3 mg/BM) in 2006 to $67.4 \mathrm{mg} / \mathrm{BM}$ (38.7-85.4 $\mathrm{mg} / \mathrm{BM}$ ) in 2013; for pigs, consumption estimates went down from $102.5 \mathrm{mg} / \mathrm{BM}(54.9-178.6 \mathrm{mg} / \mathrm{BM})$ to 76.4 $\mathrm{mg} / \mathrm{BM}$ (34.0-143.8 $\mathrm{mg} / \mathrm{BM})$ in the same time period.

For cattle, sulfonamides were the antimicrobial class that contributed the most to this decrease; for pigs, tetracyclines and sulfonamides were the classes for which consumption reduced the most (Figure 3).

\section{Discussion}

We compared different methods for stratifying antimicrobial sales data per animal species in Switzerland. This research follows the premise of the ESVAC project regarding the need to develop quantification methods of antimicrobial consumption at the species level [15].

The observed decrease of $26.2 \%$ in antimicrobial sales from 2008 to 2013 is most likely related to several concomitant reasons. Increased awareness by farmers and veterinarians about the issue of antimicrobial usage and resistance, due to several educational programmes by the FSVO, including the StAR programme [32], might have played a role in this decline. Viral diseases can lead to the use of antimicrobials to treat secondary infections [33,34]. For this reason, the implementation of the Bovine Viral Diarrhoea eradication programme and the commercialisation of Porcine Circovirus-2 vaccines might also have contributed to this reduction.

With regards to the results of the models, ED seemed to overestimate antimicrobial consumption for all species except cattle. ED does not consider variation in the levels of consumption by different species and does not take into account animal demographics, which might explain this overestimation. Indeed, it is likely 
Estimated antimicrobial consumption of different antimicrobial classes for pigs and cattle, Switzerland, 2006-2013

A. Aminoglycosides

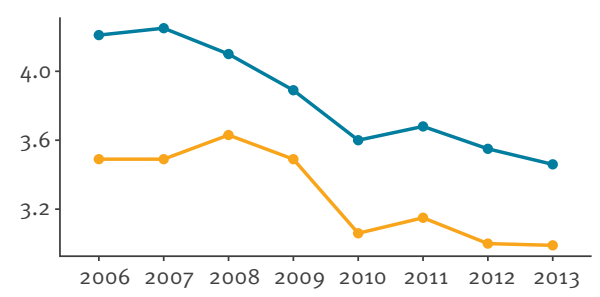

Year

\section{Others}

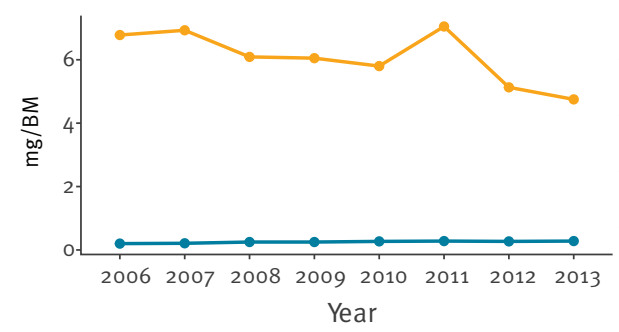

G. Tetracyclines

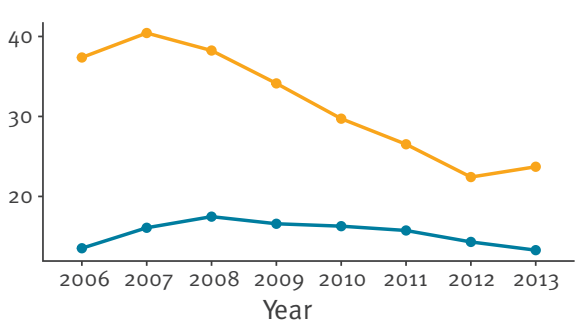

B. Cephalosporins and Fluoroquinolones

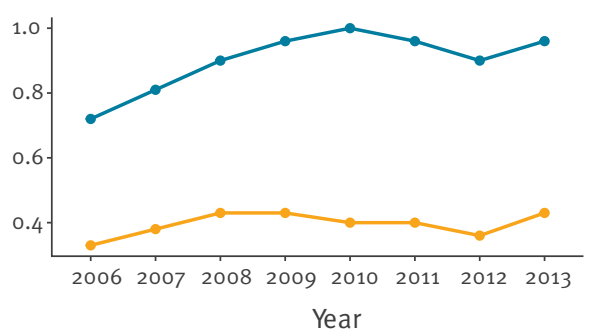

E. Penicillins

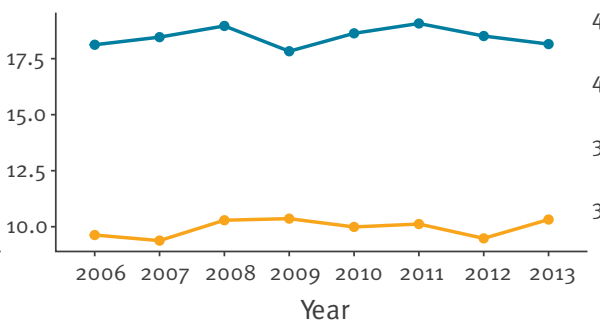

Year

\section{Macrolides}

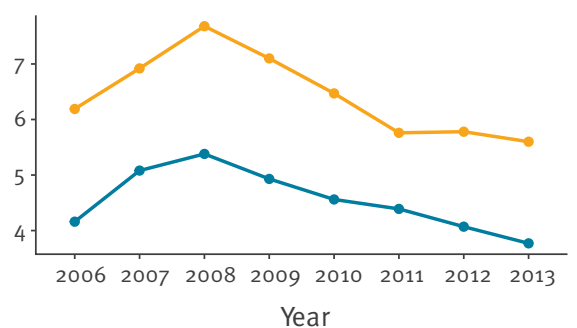

F. Sulfonamides/trimethoprim

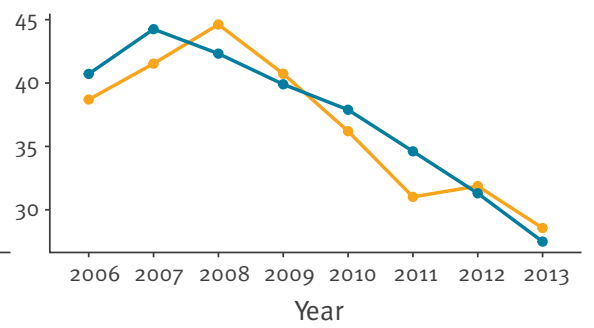

Species

$\rightarrow$ Cattle $\rightarrow$ Pigs

Results are presented in mg per kg of biomass (mg/BM). The estimates were obtained through the Longitudinal Study Extrapolation approach (LSE): sales repartition based on results from a previous field study. 'Others' includes amphenicols, quinolones (other than fluoroquinolones), lincosamides, pleuromutilins and polymixins.

that differences exist in the species repartition for multispecies products, especially in those shared between livestock and pet animals. Moreover, in Switzerland, the total cattle biomass was higher than for other species [35], largely due to the large number of dairy cattle. Given that this method did not take into account the existing number of animals in the country, it probably underestimated the usage for species with a higher total biomass and overestimated the usage for species with a lower total biomass.

The differences in the species total biomass values substantially influenced the BMD estimates, as biomass is the main driver for the repartition of sales data when using this approach. It was therefore not surprising that estimates of antimicrobial consumption by cattle were higher than those from ED. Concomitantly, extrapolated consumption by species with a lower biomass but high treatment intensity might have been underestimated.
For cattle and pigs, estimates from BMD and LSE were similar throughout the study period. The maximum difference between the two approaches was $16.2 \mathrm{mg} /$ BM for pigs and $1.9 \mathrm{mg} / \mathrm{BM}$ for cattle. For the other species, LSE estimates tended to lie between ED and BMD results. The BMD approach seems to be a useful method when field data are not available. Nevertheless, extrapolation of this method to other countries should be done with care, as it is highly dependent on animal demographics.

The LSE method calculated a steady decrease in antimicrobial consumption throughout the studied years for most of the species. Small ruminants were an exception and were associated with a minor increase over the study period, from $44.9 \mathrm{mg} / \mathrm{BM}$ (2.1-130.5 mg/ $\mathrm{BM})$ to $45.9 \mathrm{mg} / \mathrm{BM}(2.0-133.7 \mathrm{mg} / \mathrm{BM})$. Nevertheless, it should be highlighted that the uncertainty around these estimates is large.

In poultry, a steep decrease in the estimates of antimicrobial consumption (from $21.0 \mathrm{mg} / \mathrm{BM}$ (6.9-34.9 mg/ 
TABLE 1

Sales (mg per population correction unit) for different antimicrobial classes in Switzerland, 2006-2013

Veterinary antimicrobial sales in $\mathrm{mg}$ per PCU

\begin{tabular}{|c|c|c|c|c|c|c|c|c|}
\hline & 2006 & 2007 & 2008 & 2009 & 2010 & 2011 & 2012 & 2013 \\
\hline Aminoglycosides & 4.6 & 4.6 & 4.5 & $4 \cdot 3$ & 3.9 & 4.0 & 3.9 & 3.8 \\
\hline Cephalosporins & 0.6 & 0.6 & 0.6 & 0.7 & 0.7 & 0.7 & 0.7 & 0.6 \\
\hline Macrolides & $4 \cdot 4$ & $4 \cdot 9$ & 5.2 & 4.9 & 4.6 & 4.2 & 4.0 & 3.8 \\
\hline Penicillins & 15.9 & 15.9 & 16.6 & 15.8 & 16.1 & 16.4 & 15.9 & 15.8 \\
\hline Polymyxins & 2.3 & 2.0 & 1.9 & 1.9 & 1.8 & 1.7 & 1.3 & 1.0 \\
\hline Sulfonamides/trimethroprim & 35.8 & 38.2 & 37.7 & 35.1 & 32.9 & 29.6 & 27.6 & $24 \cdot 3$ \\
\hline Tetracycline & 18.5 & 20.5 & 20.3 & 18.8 & 17.7 & 16.5 & $14 \cdot 5$ & 14.1 \\
\hline Others & 0.4 & 0.6 & 0.5 & 0.5 & 0.5 & 0.9 & 0.7 & 0.7 \\
\hline Total & 82.9 & 87.8 & 87.9 & 82.5 & 78.6 & $74 \cdot 5$ & 68.7 & $64 \cdot 5$ \\
\hline
\end{tabular}

BM) to $13.9 \mathrm{mg} / \mathrm{BM}(4.8-22.6 \mathrm{mg} / \mathrm{BM}))$ was observed from 2006 to 2007 . This change might be a model artefact and not a true reduction in antimicrobial consumption. As field data were unavailable for poultry, mode values of PERT distributions might not have been very accurate, especially for those antimicrobial classes where the difference between the Min and the Max was more accentuated. In those cases, it is likely that the mode used to represent poultry's antimicrobial consumption was overestimated. In addition, this steep decrease might be partly related to the discontinuation of some products licensed for poultry between 2006 and 2008.

Pigs showed the largest decrease in antimicrobial consumption. We estimated that the pig producing industry had a particularly large antimicrobial consumption in the beginning of the study, and thus more opportunities to reduce usage were available, which might partially explain this steep decrease. Furthermore, the use of vaccines against Porcine Circovirus-2 and porcine proliferative enteritis (Lawsonia intracellularis) might also have played a role in the reduction of antimicrobial sales for use in pigs.

The wide use of Porcine Circovirus-2 vaccination in Switzerland might be associated with a lower prevalence of respiratory disease [36]. Tetracyclines are the main class used to treat respiratory disease in pigs [37]. We investigated whether LSE was able to capture this decline in specific antimicrobial classes. Indeed, tetracycline consumption showed a decline by $38.0 \%$ in pigs (larger than the decline for any other species) between 2008 and 2013.

On an antimicrobial class level, differences were observed between the classes used to treat pigs and cattle. Despite the general decrease in the usage of most antimicrobial classes, a slight increase in the consumption of cephalosporins and fluoroquinolones was estimated for cattle and pigs.
One of the most relevant benefits of having antimicrobial consumption estimates at the species level relates to the possibility of analysing them together with the resistance patterns from the national monitoring system. In Switzerland, indicator (Escherichiacoli and Enterococcus spp.) and zoonotic (Salmonella spp. and Campylobacter spp.) isolates from the three main livestock species (cattle, pigs and poultry) are collected every year. Regarding zoonotic bacteria, a general decrease in resistance was observed in Salmonella throughout the study period. This is in line with the reduction in antimicrobial consumption in the same period. For Campylobacter jejuni collected from poultry, a rise in the prevalence of ciprofloxacin resistant isolates was observed, from $12.0 \%$ in 2006 to $41.4 \%$ in 2013 . In the same period, an increase in the consumption of fluoroquinolones was observed. This is of particular relevance for public health given that fluoroquinolones are the treatment of choice for severe Campylobacter infections. With respect to Campylobacter coli from pigs, a fairly stable level of resistant isolates was found [38]; the level of antimicrobial consumption did not seem to influence the resistance pattern observed.

Concerning the indicator bacteria, it is interesting to note that an increase of ciprofloxacin-resistant E.coli isolates was observed for poultry, which was more pronounced than that for other species. On the other hand, streptomycin resistance in $E$. coli was higher for cattle and pigs when compared with broilers. This might be related to the lack of licensed aminoglycoside products for use in Swiss poultry production [38].

It is important to highlight that when assessing temporal associations between antimicrobial usage data and resistance, other factors need to be taken into account, such as cross- and co-resistance, as well as the emergence and selection of specific clones. A comprehensive analysis of these temporal patterns and the effect 


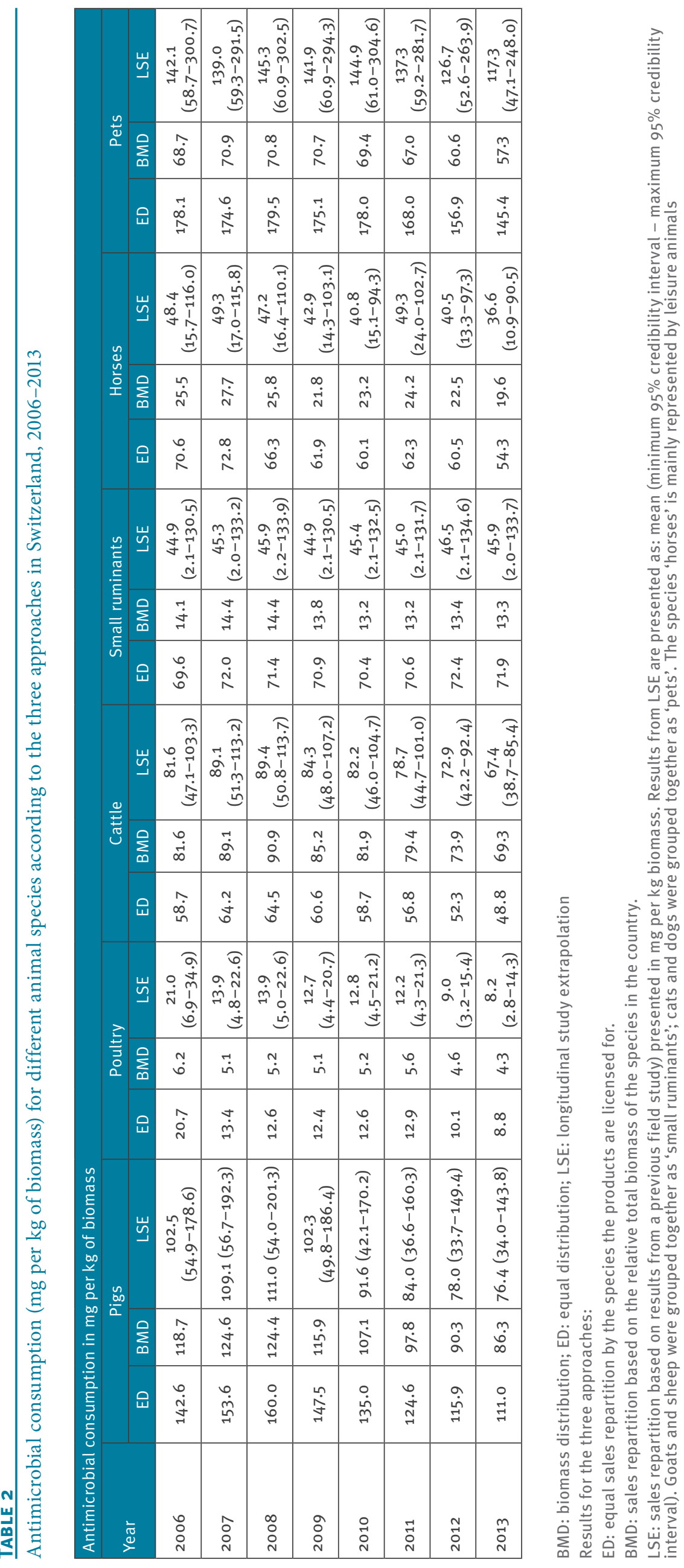


of antimicrobial consumption on the resistance of animal isolates should be performed.

Although it is not possible to validate the models, we are convinced that the LSE approach provided the best estimates. In this approach, input data for the model are derived from a longitudinal field study. These data are closer to the actual usage of antimicrobials than sales data and are therefore more likely to reflect reality. Nonetheless, the LSE method also presents some potential bias. In the first place, the field data that fed the model were from the period 2004-2005. Consumption patterns may have changed since then. However, product repartition values are not expected to vary greatly from year to year. In Switzerland, marketing authorisation holders update their repartition estimates every 5 years. These estimates are used in the Periodic Safety Update Reports (PSURs) for calculating the incidence of adverse reactions. Nonetheless, we recommend performing field studies more frequently when applying this method to yearly monitoring. Another uncertainty might arise from the number of animals at risk of being treated in the field study, which was estimated from the participating veterinarians or calculated based on the number of farms/ owners. This may have introduced some bias into the extrapolation of the field study results to a national level. When applying this method, it is advisable to have accurate estimates of the number of animals at risk of being treated in the field study. In addition to the methods presented, data for antimicrobial sales repartition per species might be obtained by asking the marketing authorisation holders [21]. It has not yet been possible to apply this valuable approach in Switzerland due to data limitations. Likewise, repartition estimates from PSURs can also provide a basis for sales stratification.

We presented three methods for extrapolating antimicrobial consumption per animal species from sales data. These approaches could be of use for countries which have not implemented detailed monitoring systems and which base their schemes on overall sales data. The best model choice in a given situation will depend on data availability. Results must always be interpreted in the light of data availability and country characteristics, and the limitations of each model must be considered. We shall also highlight that having consumption data per species enables the calculation of treatment incidence metrics, which better describe exposure to antimicrobials than $\mathrm{mg}$ per PCU. The LSE approach might also be of relevance for monitoring systems that rely on compliance of the people prescribing and administering antimicrobials to animals. In cases of imperfect compliance, a model that repartitions total sales data per species allows comparison of recorded vs expected amounts used. This might be very useful for targeted interventions to improve data quality of the monitoring system.
Acknowledgements

We would like to thank Kay Torriani for her support on the extraction of the annual sales data and for sharing details on the study by Regula et al. (2009). We would also like to show our gratitude to FSVO for funding this project.

\section{Conflict of interest}

None declared.

Authors' contributions

LPC analysed the data, interpreted the results and wrote the manuscript. CM provided expertise on the topic and assisted on the sales database management and interpretation. AC and GM contributed to the conception of the methods. GSR and IM designed the study. Furthermore, IM assisted the first author (LPC) in all steps of the study. The manuscript was revised by all the authors.

\section{References}

1. World Health Organization (WHO). Antimicrobial resistance: global report on surveillance. Geneva: WHO; 2014. Available from: http://apps.who.int/iris bitstream/10665/112642/1/9789241564748_eng.pdf?ua=1

2. Chantziaras I, Boyen F, Callens B, Dewulf J. Correlation between veterinary antimicrobial use and antimicrobial resistance in food-producing animals: a report on seven countries.J Antimicrob Chemother. 2014;69(3):827-34. DOI: 10.1093/jac/dkt443 PMID: 24216767

3. Agers $\emptyset$ Y, Aarestrup FM. Voluntary ban on cephalosporin use in Danish pig production has effectively reduced extendedspectrum cephalosporinase-producing Escherichia coli in slaughter pigs.J Antimicrob Chemother. 2013;68(3):569-72. DOI: $10.1093 / \mathrm{jac} / \mathrm{dks} 427$ PMID: 23129728

4. ECDC (European Centre for Disease Prevention and Control), EFSA (European Food Safety Authority) and EMA (European Medicines Agency). ECDC/EFSA/EMA first joint report on the integrated analysis of the consumption of antimicrobial agents and occurrence of antimicrobial resistance in bacteria from humans and food-producing animals. Stockholm/Parma/ London: ECDC/EFSA/EMA; 2015. EFSA Journal 2015;13(1):4006, 114 pp. doi:10.2903/j.efsa.2015.4006. Available from: http:// ecdc.europa.eu/en/publications/publications/antimicrobialresistance-jiacra-report.pdf

5. Lloyd DH. Reservoirs of antimicrobial resistance in pet animals. Clin Infect Dis. 2007;45(Suppl 2):S148-52. DOI: 10.1086/519254 PMID: 17683019

6. Stege H, Bager F, Jacobsen E, Thougaard A. VETSTAT-the Danish system for surveillance of the veterinary use of drugs for production animals.Prev Vet Med. 2003;57(3):105-15. DOI: 10.1016/S0167-5877(02)00233-7 PMID: 12581594

7. World Organisation for Animal Health (OIE). Chapter 6.8. Monitoring of the Quantities and Usage Patterns of Antimicrobial Agents Used in Food-Producing Animals. In: Terrestrial Animal Health Code. Version 7. Paris: OIE; 2014. Available from: http://www.oie.int/index. php?id=169\&L=0\&htmfile=chapitre_antibio_monitoring.htm

8. Mevius DJ, Sprenger MJW, Wegener HC. EU conference 'The Microbial Threat'.Int J Antimicrob Agents. 1999;11(2):101-5. DOI: 10.1016/S0924-8579(98)00093-4 PMID: 10221412

9. The Council of the European Union. Council Conclusions on Antimicrobial Resistance (AMR) - 2876th Employment, Social Policy, Health and Consumer Affairs Council meeting, Luxembourg, 10 June 2008. Available from: http://www. eu2008.si/en/News_and_Documents/Council_Conclusions/ June/o609_EPSCO-AMR.pdf

10. European Commission. Communication from the Commission on the European Parliament and the Council - Action plan against the rising threats from Antimicrobial Resistance. 15 Nov 2011; COM (2011) 748. Available from: http://ec.europa.eu/dgs/health food-safety/docs/ communication_amr_2011_748_en.pdf

11. The Council of the European Union. Council conclusions on the impact of antimicrobial resistance in the human health sector and in the veterinary sector - a "One Health" perspective

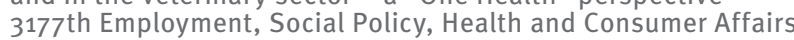


Council meeting. Luxembourg, 22 June 2012. Available from: http://www.consilium.europa.eu/uedocs/cms_data/docs/ pressdata/en/lsa/131126.pdf

12. Swiss Federal Food Safety and Veterinary Office (FSVO). Verordnung über die Tierarzneimittel (Tierarzneimittelverordnung, TAMV) [Ordinance on Veterinary Medicinal Products 2004]. Bern: FSVO; 2004. German. [Accessed 13 Oct 2016]. Available from: https://www.admin.ch/ opc/de/classified-compilation/20030705/index.html

13. European Medicines Agency (EMA). European Surveillance of Veterinary Antimicrobial Consumption. Trends in the sales of veterinary antimicrobial agents in nine European countries (2005-2009). London: EMA; 2011. Available from: http://www.ema.europa.eu/docs/en_GB/document_library/ Report/2011/09/WC500112309.pdf

14. European Medicines Agency (EMA). European Surveillance of Veterinary Antimicrobial Consumption. Sales of veterinary antimicrobial agents in $26 \mathrm{EU} / \mathrm{EEA}$ countries in 2012. London: EMA; 2014. Available from: http://www.ema.europa.eu/docs/ en_GB/document_library/Report/2014/10/WC500175671.pdf

15. European Medicines Agency (EMA). European Surveillance of Veterinary Antimicrobial Consumption. Revised ESVAC reflection paper on collecting data on consumption of antimicrobial agents per animal species, on technical units of measurement and indicators for reporting consumption of antimicrobial agents in animals. London: EMA; 2013. Available from: http://www.ema.europa.eu/docs/en_GB/document_ library/Scientific_guideline/2012/12/WC500136456.pdf

16. World Health Organization (WHO). Integrated Surveillance of Antimicrobial Resistance: Guidance from a WHO Advisory Group (AGISAR). Geneva: WHO; 2013. Available from: http:// apps.who.int/iris/bitstream/10665/91778/1/9789241506311_ eng.pdf

17. Bos MEH, Mevius DJ, Wagenaar JA, van Geijlswijk IM, Mouton JW, Heederik DJJ, Netherlands Veterinary Medicines Authority (SDa). Antimicrobial prescription patterns of veterinarians: introduction of a benchmarking approach.J Antimicrob Chemother. 2015;70(8):2423-5. DOI: 10.1093/jac/dkv104 PMID: 25907072

18. Alban L, Dahl J, Andreasen M, Petersen JV, Sandberg M. Possible impact of the "yellow card" antimicrobial scheme on meat inspection lesions in Danish finisher pigs.Prev Vet Med. 2013;108(4):334-41. DOI: 10.1016/j.prevetmed.2012.11.010 PMID: 23194892

19. Bos MEH, Taverne FJ, van Geijlswijk IM, Mouton JW, Mevius DJ, Heederik DJJ, Netherlands Veterinary Medicines Authority SDa. Consumption of antimicrobials in pigs, veal calves, and broilers in the Netherlands: quantitative results of nationwide collection of data in 2011.PLoS One. 2013;8(10):e77525. DOI: 10.1371/journal.pone.0077525 PMID: 24204857

20. Wageningen University. Survey data and statistical analysis. [Accessed 26 Oct 2016]. Available from: http://www.wur.nl/ en/Research-Results/Projects-and-programmes/MARANAntibiotic-usage/Materials-methods/Survey-data-andstatistical-analysis.htm.

21. National Agency for Veterinary Medicinal Products - French Agency for Food Environmental and Occupational Health Safety (ANSES). Sales survey of Veterinary Medicinal Products containing Antimicrobials in France - 2009. Fougères: ANSES; 2011;10:411. Available from: https://www.anses.fr/en/system/ files/ANMV-Ra-Antibiotiques2009EN.pdf

22. Swiss Agency for Therapeutic Products (Swissmedic). Information für Fachpersonen Antibiotika für die Veterinärmedizin : Vertriebszahlen der Jahre 2004 bis 2006 [Information for professionals. Antibiotics in veterinary medicine: Sales data for the years 2004 to 2006]. Bern: Swissmedic; 2007. German. Available from: https://www. swissmedic.ch/marktueberwachung/00135/00136/00181/ index.html?lang=en

23. Swiss Agency for Therapeutic Products (Swissmedic). ARCH-Vet Report on the sales of antibiotics for veterinary use and antibiotic resistance monitoring of livestock in Switzerland 2012 (Short version). Bern: Swissmedic; 2012. Available from: https://www.swissmedic.ch/ marktueberwachung/00135/00136/00181/index.html?lang=en

24. Institut für Veterinärpharmakologie und -toxikologie [Institute of Veterinary Pharmacology and Toxicology]. Tierarzneimittel Kompendium der Schweiz [Veterinary Swiss Drug Compendium]. Zurich: 2015. German. [Accessed 8 Dec 2015]. http://www.vetpharm.uzh.ch/perldocs/index_i.htm

25. European Medicines Agency (EMA). Questions and answers on preparation, management and assessment of periodic safety update reports (PSURs). London: EMA; 2013. [Accessed 13 Oct 2016]. Available from: http://www.ema.europa.eu/ema/index. jsp?curl=pages/regulation/q_and_a/q_and_a_detail_o00041. jsp
26. Proviande Genossenschaft [Proviande Association]. Der Fleischmarkt im Überblick 2014 [Overview on the meat market 2014]. Bern: Proviande; 2015. German. Available from: https:// www.proviande.ch/de/medien/page/2015/der-fleischmarkt-imueberblick-2014.htm

27. Société pour l'alimentation des animaux familiers [Swiss Society for Pet Nutrition]. Population canine 1995-2012 [Dog population 1995-2012]. French. [Accessed 8 Dec 2015]. Available from: http://www.vhn.ch/wp-content/ uploads/2012/10/Dog-Population.jpg

28. Société pour l'alimentation des animaux familiers [Swiss Society for Pet Nutrition]. Population de chats 1995 -2012 [Cat population 1995-2012]. French. [Accessed 8 Dec 2015]. Available from: http://www.vhn.ch/wp-content/ uploads/2012/10/Cat-Population.jpg

29. Regula G, Torriani K, Gassner B, Stucki F, Müntener CR. Prescription patterns of antimicrobials in veterinary practices in Switzerland.J Antimicrob Chemother. 2009;63(4):805-11. DOI: $10.1093 / j a c / d k p o 09$ PMID: 19218273

30. R Core Team. R: A Language and Environment for Statistical Computing, 2013. Available from: https://www.r-project.org/

31. Andraud M, Rose N, Laurentie M, Sanders P, Le Roux A, Cariolet $R$, et al. Estimation of transmission parameters of a fluoroquinolone-resistant Escherichia coli strain between pigs in experimental conditions. Vet Res (Faisalabad). 2011;42(1):44. DOI: 10.1186/1297-9716-42-44 PMID: 21366902

32. Swiss Federal Food Safety and Veterinary Office (FSVO). Nationale Strategie Antibiotikaresistenzen (StAR) [National Antibiotic Resistance Strategy (StAR). German. [Accessed 13 Oct 2016]. Available from: https://www.blv.admin. $\mathrm{ch} / \mathrm{blv} / \mathrm{de} / \mathrm{home} / \mathrm{das}-\mathrm{blv} / \mathrm{strategien/nationale-strategie-}$ antibiotikaresistenzen.html

33. Brodersen BW. Bovine viral diarrhea virus infections: manifestations of infection and recent advances in understanding pathogenesis and control.Vet Pathol. 2014;51(2):453-64. DOI: 10.1177/0300985813520250 PMID: 24476940

34. Drew TW. A review of evidence for immunosuppression due to porcine reproductive and respiratory syndrome virus.Vet Res. 2000;31(1):27-39. DOI: 10.1051/vetres:2000106 PMID: 10726636

35. European Medicines Agency (EMA). European Surveillance of Veterinary Antimicrobial Consumption. Sales of veterinary antimicrobial agents in 25 EU / EEA countries in 2013. Fifth ESVAC report. London: EMA; 2015. Available from: http:// www.ema.europa.eu/docs/en_GB/document_library/ Report/2015/10/WC500195687.pdf

36. Chae C. Porcine respiratory disease complex: Interaction of vaccination and porcine circovirus type 2 , porcine reproductive and respiratory syndrome virus, and Mycoplasma hyopneumoniae.Vet J. 2016;212:1-6. DOI: 10.1016/j. tvjl.2015.10.030 PMID: 27256017

37. De Briyne N, Atkinson J, Pokludová L, Borriello SP. Antibiotics used most commonly to treat animals in Europe.Vet Rec. 2014;175(13):325. DOI: 10.1136/vr.102462 PMID: 24899065

38. Swiss Federal Office of Public Health (FOPH) and Swiss Food Safety and Veterinary Office (FSVO). Usage of antibiotics and occurrence of antibiotic resistance in bacteria from humans and animals in Switzerland - Joint Report 2013. Bern: FOPH; 2015. Available from: http://www.anresis.ch/files/pdf/BAG_ Antibiotikaresistenz_Bericht_WEB.pdf

\section{License and copyright}

This is an open-access article distributed under the terms of the Creative Commons Attribution (CC BY 4.0) Licence. You may share and adapt the material, but must give appropriate credit to the source, provide a link to the licence, and indicate if changes were made.

This article is copyright of the authors, 2017. 